

\section{A animação na era digital: um estudo de casos no Japão e nos EUA}

\section{Animation in the digital era: a case report in Japan and in the USA}

\section{Resumo}

O presente artigo busca analisar dois filmes cujas técnicas de animação estudaram novas propostas estéticas ao cinema contemporâneo, cada um à sua maneira. Pensando o cinema como uma mídia capaz de fazer convergir os mais diversos meios, e associando à animação o poder de representar qualquer coisa capaz de ser imaginada, o artigo busca nos filmes Uma Cilada Para Roger Rabbit (Who Framed Roger Rabbit, Robert Zemeckis, 1988) e O Fantasma do Futuro (Kôkaku Kidôtai, Mamoru Oshii, 1995) a descrição de um cinema digital como uma nova mídia, atravessando fronteiras físicas e mercadológicas, capaz de produzir uma série específica de sentidos previamente improváveis ao seu meio e que se predispõe, tal como o cinema sempre se predispôs, a estudar novas formas de criar imagens e signos para as mesmas.

\section{Palavras-chave}

Cinema digital; animação; história do cinema; imagem; tecnologia.

\section{Abstract}

This paper analyzes two films whose animation techniques studied new aesthetic proposals in contemporary cinema, each one in its own manner. Thinking cinema as a media capable of converging various media, and combining the power of animation to represent anything able to be imaginable, the article seeks in the movies Who Framed Roger Rabbit (Robert Zemeckis, 1988) and Ghost in the Shell (Kôkaku kidôtai, Mamoru Oshii, 1995) the description of a digital cinema as a new media, crossing physical and marketing borders, able to produce a specific series of previously unpredictable meanings to their environment and that predisposes, such as cinema has always done, the exploration new ways of creating images and signs for them.

\section{Keywords}

Digital cinema; animation; history of film; image; technology.

MAGINARROO 


\section{A inserção do cinema}

O cinema sempre travou suas próprias revoluções: do cinescópio ao cinematógrafo, do som aos binários que vão além de uma possibilidade narrativa interativa. Ao olharmos para o momento presente em que múltiplos meios de produção e de pós-produção circulam, percebemos que o tempo ou o financiamento dessas tecnologias são quase os únicos limites dentro do que pode ser realizado em cinema. Por isso, a questão do cinema digital torna-se a própria discussão do cinema e das suas reavaliações, pois coloca em discussão a essência da linguagem cinematográfica, resumindo o cinema àquilo cujo fruto pertence à ordem das imagens em movimento.

Assim, para realizar o estudo de como o cinema digital trouxe modificações para a produção cinematográfica de animação, é preciso saber como esse campo se configurou. A análise perpassa os dois grandes produtores de animação, os Estados Unidos e o Japão, justamente pela grande aderência aos seus produtos no mercado mundial. É também nas suas oposições e similaridades que descobrimos as diferentes formas de tratamento que novas tecnologias podem assumir esteticamente.

No cinema japonês do pós-guerra, o mercado era controlado pelo The Big Three, muito próximo ao sistema de estúdio de Hollywood. O quadro modificou-se por volta de 1961, com o grupo do Art Theather Guild, que vinha apoiando o cinema independente de autores como Nagisa Oshima, Yoshige Yoshida, Kaneto Hindo, entre outros. Paralelamente a essa geração de novos diretores live-action, surgia um grupo de animadores especializados em longas-metragens de ficção e fantasia, conhecidos como Animê. Vários dos grandes sucessos cinematográficos japoneses da década de 1980 foram filmes de animação, como Akira (Katsuhiro Otomo, 1988). Esses animadores trabalhavam com orçamentos baixos, o que acabava por limitar os efeitos de profundidade e de grandes movimentos que podiam realizar, tornando-os familiarizados a trabalhar com movimentos leves e estáticos. $O$ anime se tornou extremamente rentável e modificou tanto o cinema japonês quanto a forma como a animação era vista incrementando um mercado que até então era claramente dominado pelas animações estadunidenses.

Em relação à animação estadunidense, a Disney iniciou suas produções com o filme Branca de Neve e os 7 Anões (Snow White and the Seven Dwarfs, David Hand, 1937). Nessa "Era de Ouro", como é chamada, muitas técnicas da animação foram desenvolvidas como as conhecemos: a técnica de Model ou Puppet Animation, a Clay Animation, a Pixillation, entre outras. No entanto, a revolução dentro dos estúdios de animação chegaria com as imagens animadas inteiramente por computador, com as tecnologias que já vinham se aprimorando até meados dos anos 1980. Na década consagrada, o primeiro filme a incluir animação por computador foi Tron - Uma Odisséia Eletrônica (Steven Lisberger, 1982), produzido pela Disney. Na década de 1990, várias empresas começaram a desenvolver tecnologias para aumentar as possibilidades da animação digital, como George Lucas com a Industrial Light \& Magical e Steve Jobs com a Pixar Animation. Assim, com as novas tecnologias foi possível unir também live-action com animação.

A cultura da imagem em movimento no século vinte surge da oposição entre os estilos de animação e o cinema. Diversas técnicas que permitiam a criação de imagens, tais como os jogos de espelhos, fundos de projeções e efeitos ópticos foram empurradas para a periferia. Hoje, com a mudança do meio digital, essas técnicas "marginalizadas" voltam ao centro. Assim a lógica de produção no cinema está sendo redefinida pelo processo digital, que permeia todas as etapas de um filme, não sendo apenas uma ferramenta de pós-produção, como costumava ser.

\section{As realidades digitais de O Fantasma do Futuro (Kôkaku Kidôtai,}

Mamoru Oshii, 1995)

Em entrevista dada para o making-of do filme Ghost in the Shell: Innocence (Inosensu: Kôkaku kidôtai, Mamoru Oshii, 2004), o diretor fala sobre a inserção de um cachorro nesta continuação. Diz ele:

Os cães foram fabricados pelos seres humanos. Eles não são animais selvagens. O homem retirou-os da natureza e fez deles o que eles são. A história da humanidade, sua cultura e civilização, sempre foram sobre a criação de fantoches. A humanidade sempre transformou de acordo com aquilo que concorda com a sua imagem. Mas, por mais que eu pense sobre isso, é sempre sobre degeneração ${ }^{5}$.

Mesmo referindo-se ao filme que é a continuação do aqui abordado, acreditamos que é sobre este ponto de tratamento psicológico dos personagens, já evidentemente presente no primeiro filme, e sobre o seu reflexo no uso do digital, que fazem de O Fantasma Do Futuro um filme de estudo relevante para aqueles que pretendam pesquisar o uso dos meios digitais nos filmes de animação.

Reconhecido por seus avanços na robótica, as ficções produzidas no Japão são ótimos casos para o estudo destas "entidades". Aproximamo-nos, aqui, da ideia de Hartmann, segundo o qual: "o ser e o ente se distinguem da mesma maneira que se distinguem a verdade e 
o verdadeiro, a realidade do real" (Hartmann, 2012, p. 40). Como uma proposta de simbiose entre as duas esferas de existência anunciadas pelo filósofo alemão, que diz ser ilógico se referir a um sem se referir ao outro, Shirow Masamune, criador da história que dará origem ao filme, nos apresenta o Projeto 2501, entidade cujo nascimento de sua consciência, fugindo da ideia Flusseriana de que aquilo que é programado pelo homem estará limitado ao seu conhecimento e capacidade de programação, dá-se na profusão caótica de informações de uma base de dados mundial. Desconhecendo os limites virtuais, é realidade e real ao mesmo tempo.

Como viria a ser referido por Thompson e Bordwell no seu livro Film Art: An Introduction (2003), a animação japonesa já conhecia, em meados da década de

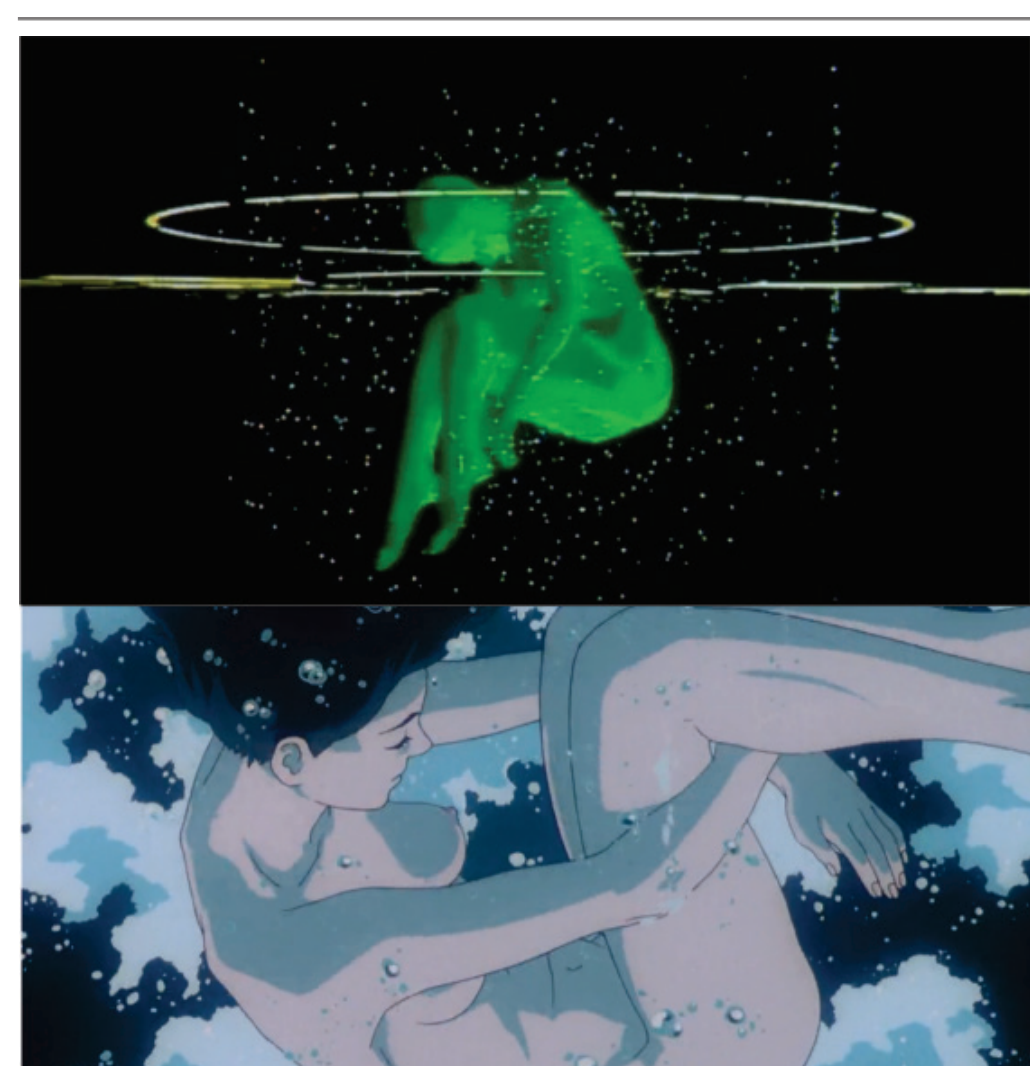

Figura 1: cena de O Fantasma do Futuro noventa, as possibilidades que a manipulação digital trazia para as etapas de produção de um anime ${ }^{6}$. Porém, houveram sempre de restringir-se à pós-produção e ao pensamento de que o seu uso estaria associado aos ajustes e à edição, além de haver um pensamento coletivo quase concordante que dizia que a estética digital deveria sempre buscar a semelhança com aquilo que foi animado à mão. Deste modo, nosso maior acesso para análise são filmes que usam as possibilidades digitais em uma estética definida já por aquilo que foi animado de forma tradicional.

Em O Fantasma do Futuro temos, desde o princípio, como podemos ver pela sequência de título [Figura 1], um estudo de formas de representação que se seguirá ao longo de todo o filme, onde o digital existe já como animação autônoma, dividindo espaço e significante com o filme como um todo. Aqui, o digital tomará as proporções de uma realidade para além da imaginação humana, onde a robótica tornou-se uma base sólida da civilização e das relações de poder dentro da sociedade. $\mathrm{Na}$ abertura do filme vemos os passos de criação de um cyborg, mais propriamente a da personagem principal: a Major Motoko. Representada enquanto um corpo em construção, nós vemos as suas peças serem montadas e postas em ordem, sendo alternados planos de animação tradicional com imagens em CGl, muitas vezes manifestando a existência destas duas realidades, mostrando a continuidade das ações do seu corpo nos dois modelos de animação. Enquanto ele emerge de um líquido que o colore de branco, a imagem em CGI aparece mostrando o final deste processo; e enquanto, mais adiante, a CGI mostra um corpo em posição fetal a girar em um espaço digital, logo somos levados a um plano onde o corpo, animado à mão, cai em um ambiente líquido.
Como um ambiente de nascimento, essa cena introduz ao público uma posição crucial para a animação digital dentro do filme. Quando insere a personagem no mundo digital, com o fundo negro e as aplicações digitais em verde, é como se propusesse o simulacro de um útero, onde funções externas ao corpo trabalham para a formação do mesmo. Levando a sério esta metáfora, não é sem propósito que a primeira cor tomada pelo corpo, após a desintegração do branco que cobriu a sua estrutura de ferro, seja um tom claro de roxo, como um bebê recém-nascido. Por fim, descobrimos no enredo que os cyborgs têm o livre arbítrio de pedir seus corpos e memórias biológicas de volta ao governo se quiserem demitir-se. Ideia esta que transforma a ação do genérico em um segundo nascimento, tendo sido transformado em um fantasma, em uma entidade que já não é mais aquilo que já foi, mas que habita agora uma nova concha. É outro real inserido em outra realidade.

No último plano da abertura, o apartamento escuro serve como moldura para uma grande janela retratando a cidade onde vive a personagem e se desenrola o filme. A cidade, ao longo do gênero de ficção-científica japonês, é um símbolo da concretude e do avanço tecnológico. Pode-se dizer que em uma maioria significativa de projetos que envolvem robôs, a cidade tem uma relação íntima com a vivência do homem consigo mesmo. Nos trabalhos de Mamoru Oshii isso não é diferente, até certa medida. No artigo States of Emergency: Urban Space and the Robotic Body in the Metropolis Tales Lawrence Bird (2008) aborda a temática do corpo robótico e da sua relação com a cidade quase que como um gênero fílmico. Estabelecendo a importância das relações que o homem tem com a arquitetura que o circunda, e levando ainda em consideração que o Japão

72 PORTO ALEGRE | v. 19 | n. 32 | 2014 | pp. 70-77 Sessões do Imaginário 
foi o único país até hoje a vivenciar um ataque por armamentos atômicos, ele argumenta que a destruição das cidades, e das sociedades humanas interligadas a elas, tornou-se uma imagem que chega perto de definir a animação japonesa. Entre os muitos exemplos que tinha a sua disposição, Bird escolhe a animação $\mathrm{Me}$ tropolis (Metoroporisu, Rintaro, 2001) para demonstrar a potência deste suposto gênero. Dividindo uma linha tênue de significações com o filme de Fritz Lang, a animação japonesa aborda o fato de que para a revolução dos robôs acontecer, eles precisam destruir a cidade como ela é conhecida, mas ao fazerem isso destroem também a si mesmos. Ou seja, a culminação da destruição do status quo implica na transformação radical ou total da cidade e de todos os processos tecnológicos que ajudaram a construí-la. Muitos teóricos do anime relacionam esta dualidade destrutiva à psique da cultura japonesa do pós-guerra aliada à latente ideia de que a robótica é o evidente destino humano. Para os japoneses, a destruição em massa de uma cidade implica na destruição do processo histórico que transformaria o presente no futuro esperado, forçando o presente a ser novamente passado, começando novamente a construção de todas as bases sociais.

Porém, como havíamos referido anteriormente, $O$ Fantasma do Futuro apresenta um decorrer que não se encaixa neste motivo narrativo com total precisão, apesar de não deixar de dialogar profundamente com o mesmo. Masamune e Oshii trabalharam a cidade e sua relação com os homens e os cyborgs a partir da perspectiva dos seres que a habitam. Para que possamos esclarecer quem são estes "seres", voltamos à ideia de entidade. Aqueles que configuram a cidade são todos aqueles que têm consciência de suas ações e liberdade individual para configurarem o seu próprio destino.
Deste modo, cyborgs feitos à imagem e semelhança do homem, capazes de perceberem os mesmos sentimentos e vivenciarem as mesmas experiências químicas e biológicas, como alimentar-se, dormir e metabolizar álcool, são agentes tão configuradores da cidade quanto os seres humanos totalmente biológicos. A única diferença entre humanos e cyborgs acaba sendo, como é referida pela personagem principal, a capacidade humana de ter uma individualidade mais referenciada que a dos robôs, por estes terem apenas um "eu", superpoderoso e imutável, enquanto o homem acumula, ao longo de sua vida, os diversos "eus" ao mesmo tempo, que dialogam entre si e conformam a identidade humana. Nesta mesma cena ainda vemos o uso do digital da forma mais assimilada pela animação, exemplo não tão comum para o filme. À medida que o discurso sobre o estado dos homens e dos cyborgs desenvolve-se, percebemos os prédios atrás da personagem sofrendo uma constante curvatura e avanço no plano. Entendemos esta cena, afinal, como a expressão de potência em O Fantasma do Futuro para a relação daquilo que Bird vai determinar como as consequências da relação entre o bem estar da cidade e do homem:

A arquitetura e as formas urbanas tomam o ser humano como sua medida, literal e metaforicamente. A destruição dividida destas figuras mutuamente delimitadas - humano e espaço urbano - implicam em uma crise moderna sobre aquilo que significa ser humano e sobre o que significa viver em uma comunidade. (Bird, 2008, p. 127)

É neste sentido de destruição daquilo que significa conviver com esta sociedade que Mamoru Oshii afirma a criação dos robôs à imagem e semelhança do homem como um ato de degeneração. Quando o homem cria entidades sobre-humanas, e dá-lhes a liberdade do raciocínio humano, a vivência do que é comum ao corpo que morre transformasse na mesma do corpo sem limites, e a cidade se transforma em uma cortina de corpos em diferentes estados de existência capazes de viver as mesmas coisas - é a experiência de Gregor Samsa, em Kafka, finalmente transformado em barata por tratarem-no como uma, aqui elevada ao extremo social.

Em uma cena de passagem, o filme retrata essa vivência multipartida enquanto Motoko vagueia pela cidade e a observa. Mostra uma cidade que nunca se finaliza, em progressiva construção e reconstrução, enquanto limita o homem àquilo que é baixo propagandista e velho. Ao meio da cena começa a chover, e assim é como se todos os seres fossem unidos por aquela vivência. Capaz de unir todos sobre um evento que ainda não é determinado pela simples vontade humana. O laço primordial que une todas as formas de corpos que passam pela cena, dos homens, dos cyborgs, das silhuetas em propagandas coloridas e dos manequins em vitrines. O corpo, em O Fantasma do Futuro, é mesmo apenas uma casca, e a sua destruição não significa o fim da civilização, mas o nascimento de um motivo para recomeçar de um modo ainda mais automático e menos humano ao mundo.

No artigo de pesquisa Framing attention in Japanese and American comics: cross-cultural differences in attentional structure (Cohn, Taylor-Weiner e Grossman, 2012), os autores propõe uma análise detalhada das diferenças apreensíveis entre as histórias em quadrinhos ocidentais, mais especificamente os comics estadunidenses, dos mangás japoneses. Abrangendo um estudo definitivamente estruturalista, os pesquisadores preo- 
cupam-se em analisar, de forma matemática, as porcentagens de papel em branco entre os quadros desenhados, a sua forma de ocupar as folhas, os seus ângulos e etc. Apesar de seguir um rumo que não diz respeito ao trabalho aqui tratado, este artigo trás ao público uma dedução analítica que acaba por resumir muito bem uma das principais diferenças entre estas formas de arte. Dizem eles que enquanto o quadrinho estadunidense tende o seu foco na cena em si, no seu todo, o mangá parece focar sua atenção nos personagens, em caracterizá-los individualmente, fazendo parte do todo da cena. Deste modo:

Depois de ver as cenas, estadunidenses descrevem principalmente os objetos salientes, enquanto os asiáticos descrevem significativamente mais o contexto circunjacente. Estadunidenses também tendem a notar diferenças em objetos focais de animações que apresentam pequenas mudanças, enquanto asiáticos reparam mudanças nos ambientes mais amplos e em relações entre objetos. (Cohn, Taylor-Weiner e Grossman, 2012, p. 240)

Esta diferença acaba sendo crucial para compreender as decisões de montagem e apresentação de muito do conteúdo gerado na animação japonesa. Sendo os animês, na sua maioria, adaptações de mangás, é mais que conveniente que as estruturas da história ultrapassem o meio, a fim de tentar causar no novo meio uma percepção semelhante àquela do mangá.

Compreendida esta diferença, passamos para a análise do que é a sua consequência direta. Em um filme como O Fantasma do Futuro, o cinema digital assume não apenas a forma de uma técnica, mas mostra ter ganhado um estudo estético de suas possibilidades. Neste sentido, o realizador fez questão de usar a CGI não como uma forma de acrescentar um realismo maior à estética da animação em células, mas sim usá-la como uma forma de interpretar e representar uma particularidade específica e problemática do filme: como se desenha uma nova realidade? O que Oshii fez foi levar-nos a compreender o cinema digital como uma possibilidade de explorar estéticas e grafismos inacessíveis com as técnicas de animação à mão. Unindo duas formas distintas de representar esta nova dimensão, se torna visível a preocupação em demonstrar esta fisicalidade das imagens digitais dentro da história retratada. Neste novo mundo, as imagens ganham uma tridimensionalidade evocatória de uma presença física demarcada no espaço, onde a vivência da sua virtualidade tenha se transformado em uma constante capaz de determinar a relação das pessoas com as imagens e, no caso dos cyborgs, da realidade externa do mundo com a sua realidade virtual em rede. A imagem já não está diante dos personagens, mas sim entre os personagens e o ponto de vista da câmera. Não é mais o resultado do caminho entre personagem e câmera, mas sim um processo físico do caminho.

Um distinto ponto sobre o uso do digital dentro do filme observa o modo oriental de pensar a animação. 0 animê acabou por herdar do cinema uma preocupação que percebemos não ter latência na grande maioria das animações ocidentais: a preocupação pelo ponto de vista. Nos animês são facilmente reconhecíveis artifícios que mergulham o espectador dentro dos pensamentos - vozes em off, câmeras lentas, close-ups, entre outros. Dessa forma, a animação ganha uma dimensão pessoal incomum às animações ocidentais, onde o enfoque ba- seia-se costumeiramente na ação física evidente dos personagens, com planos preocupados em mostrar o todo da ação que se desenvolve no espaço. Desta forma, o que vemos são imagens de um mundo ao alcance das experiências tecnocratas e dos seus fantoches super-humanos. O espectador passa a ver pelos olhos da máquina, assumindo um corpo e sujeitando-se às formas de percepção do mesmo. E é sobre esta outra realidade, sobre este novo mundo onde um cérebro pode ser ligado em rede com outros cérebros, que o filme constrói o seu discurso a cerca das raízes da animação, dando diretrizes ao pensamento da técnica enquanto ferramenta capaz de motivar novos rumos aos discursos cinematográficos pré-existentes. A animação abandona a simples reprodução de imagens abordadas em outras mídias, e passa a ser também o pensamento sobre a própria animação e o ato de criar imagens especificamente para esta nova mídia.

Entre o cinema e a animação de Uma Cilada para Roger Rabbit (Who Framed Roger Rabbit, Robert Zemeckis, 1988)

Antes de tudo, um marco na história do cinema. As técnicas de integração da linguagem cinematográfica com a animação já haviam sido divulgadas nas décadas de trinta e quarenta, porém o que tornou este filme um marco foi esta integração marcar todo o filme, assim como pela primazia de sua produção. O filme pensa intimamente a ligação da animação e do live-action, e mantém sempre uma visão dupla de realidades: duas estéticas, cinema e animação; a realidade e o animado; dois gêneros, noir e animação; a comédia e o suspense. Para abordar estes duplos retratados, os personagens principais, Roger e Eddie, representam uma visão/es- 
tética, compondo assim um discurso de metacinema e meta-animação.

A história se passa em Hollywood de 1947, não coincidentemente a época auge tanto do filme noir quanto da animação estadunidense. A estética da "Era de Ouro" da animação estadunidense é representada pelo humor do cartoon, de cores fortes e vivas, característico do technicolor, a estética do nonsense e suas próprias leis físicas. Em oposição vemos o universo noir que é construído através da história policial de investigação e de intrigas, o contraste de tons sóbrios, a música ao estilo jazz com motivos de suspense e sensualidade, assim como Jéssica Rabbit é a personificação da femme fatal.

A apresentação dos créditos e do título se dá ao fundo de um som de jazz, que é quebrado por ritmo e cores. O fundo preto é trocado para o colorido e a música que antes tinha um ar misterioso e sedutor se torna "cartoonizada". O começo também é uma sequência animada que remete de forma direta às produzidas da "Era de Ouro" da animação estadunidense: o formato dos créditos de entrada do estúdio; a apresentação dos personagens; o nome do episódio; a direção de produção; tudo criado especificamente para o filme, de modo que ficcionalmente funcionasse como se estivesse na década de quarenta. O sketch animado que começa o filme é interrompido pelo diretor Raul, trazendo à animação as implicações das filmagens de cinema live-action: a necessidade de um set de filmagem; a relação entre diretores e atores, assim como a relação personagem/ator, que não são imagináveis no cinema de animação. Nesta cena Valient nos é apresentado, saindo de um canto escuro, típico noir.

A trilha sonora é um importante elemento de intersecção dos dois gêneros abordados no filme, de maneira que sempre conseguimos reconhecer uma música ao estilo noir e outra ao estilo animação, e seus modos de introdução nas cenas são tons importantes do filme. Estando entre as transições de planos, evidencia uma profunda ligação entre os dois estilos, de maneira a não ser genuinamente nem um nem o outro. A música de trilha sonora de "estilo desenho animado" começa antes do final da cena do estúdio, momento em que nos mostra o aspecto noir, e adentra na cena em que Valient entra no gabinete do Sr. Maroon, de onde a música esta inserida de forma diegética. Sr. Maroon se mostra um personagem tão caricato como um desenho - rabugento, de sobrancelhas arqueadas - mas o cenário referente a esse personagem trás artifícios do filme noir tais como uma parede falsa, escondendo uma sala com os arquivos cinematográficos. Assim como a organização cenográfica representa o mundo real e monótono - troféus, bebidas, tons sóbrios e etc - em que Eddie está inserido, se propõe um contraste com o mundo animado visto através da janela: com desenhos circulando livremente pelo pátio do estúdio. A trilha sonora começa novamente antes do término da cena no interior do gabinete para o exterior do estúdio, mas, desta vez, com um tema "mais noir". Valient adentra o mundo da animação, tanto física quanto metaforicamente. A música representa o submundo de Eddie, que é sobreposta pela música própria da cena, esta diegética, com um saxofonista ensaiando O Aprendiz de Feiticeiro com as vassouras. Originalmente esta peça, apresentada no filme Fantasia (Samuel Armstrong, 1940), leva o timbre do fagote. Sua mudança para o saxofone, instrumento de timbre comumente associado às trilhas sonoras do cinema noir, evidencia mais uma vez a vontade de gerar esse cruzamento entre os gêneros.

O metacinema e os duplos continuam a serem abordados ao longo do filme. Na cena em que Roger descobre a suposta traição por parte de Jéssica, recebe uma série de fotografias que comprovam o ato (que ele chama de Patty (ake), e, para vê-las, cria uma sequência animada dando movimento à sequência de fotografias. Voltamos tanto ao princípio do cinema quanto da animação. Nesta mesma cena, marcando algo próprio do cinema, em uma troca de ângulos de visão, há raccords subjetivos que mostram as mãos enluvadas de Roger observando as fotografias, enquanto estas, por conterem Jéssica nelas, também pertencem tanto ao mundo do live-action quanto da animação.

Para se chegar a uma produção que marcou de forma ímpar este tipo de experiência técnica cinematográfica, para que se tornasse possível usar tanto o chromakey quanto as fotografias de fundo fixo, onde são sobrepostas animações feitas em células transparentes, que exige uma atuação marcada de forma rígida, a produção do filme foi dividida em três partes:

1 - Filmagens: As filmagens eram minuciosamente marcadas, já tendo um estudo preciso do quadro a quadro de cada cena. Bonecos dos personagens animados, de borracha e de tamanho real, foram utilizados para marcação do espaço dos mesmos. Para a interação desenho/objeto, ventrículos manipulavam, através de fios, os objetos utilizados nas cenas. Para manter o tempo, ritmo e continuidade das cenas, os dubladores estavam presentes no set.

2 - Animação: Essa etapa, inteiramente feita a mão, passou por dois processos:

a) Trabalharam sobre as filmagens de modo a sobrepor os personagens animados sobre os mecanismos utilizados anteriormente, assim como todo o acertar do enquadramento e tamanho do personagem na cena;

b) Devidamente marcados, os personagens eram trabalhados quadro a quadro de forma a ganhar movimen- 
to. Desenvolvidas suas ações, os desenhos são pintados e prontos para serem sobrepostos ao material filmado.

3 - Manipulação digital: Frame por frame, as células transparentes são sobrepostas às cenas filmadas, e sobre elas é criada uma terceira camada, onde as cores, luzes e sombras são tratadas de maneira a integrar os processos anteriores.

Uma cena capaz de relacionar o total destes processos técnicos é quando Eddie investiga Jéssica no bar onde ela trabalha. No começo da cena, vemos Pato Donald e Patolino ao piano, encontro marcante entre famosos personagens de produtoras rivais, demonstrando a grandiosidade do projeto. A cena é marcada também pelo trabalho campo e contracampo, assim como sobressaem os reflexos e a iluminação, elementos que até então não tinham tanto peso no processo de animação [Figura 02]. Esta cena monstra o domínio no tratamento da luz, na transparência e brilho do vestido, quase material. Trabalho este que só pode ser feito por tratamento digital. A cena no bar nos revela o extremo da interação dos atores e objetos reais. Podemos ver esta incansável produção por todos os outros personagens presentes no bar, a exemplo dos pinguins que trabalham como garçons e carregam bandejas - estas que durante as filmagens tiveram de ser conduzidas por ventríloquos no subsolo do set de filmagens.

\section{Uma cilada para Roger Rabbit e}

O fantasma do futuro: realidade e corpo

Em uma pesquisa que aborda o cinema digital dentro da animação, pareceu-nos central o pensamento sobre o material que seria estudado. Para que pudesse haver uma abrangência mínima de formas de pensar as consequências do cinema digital dentro da animação, foi decidido

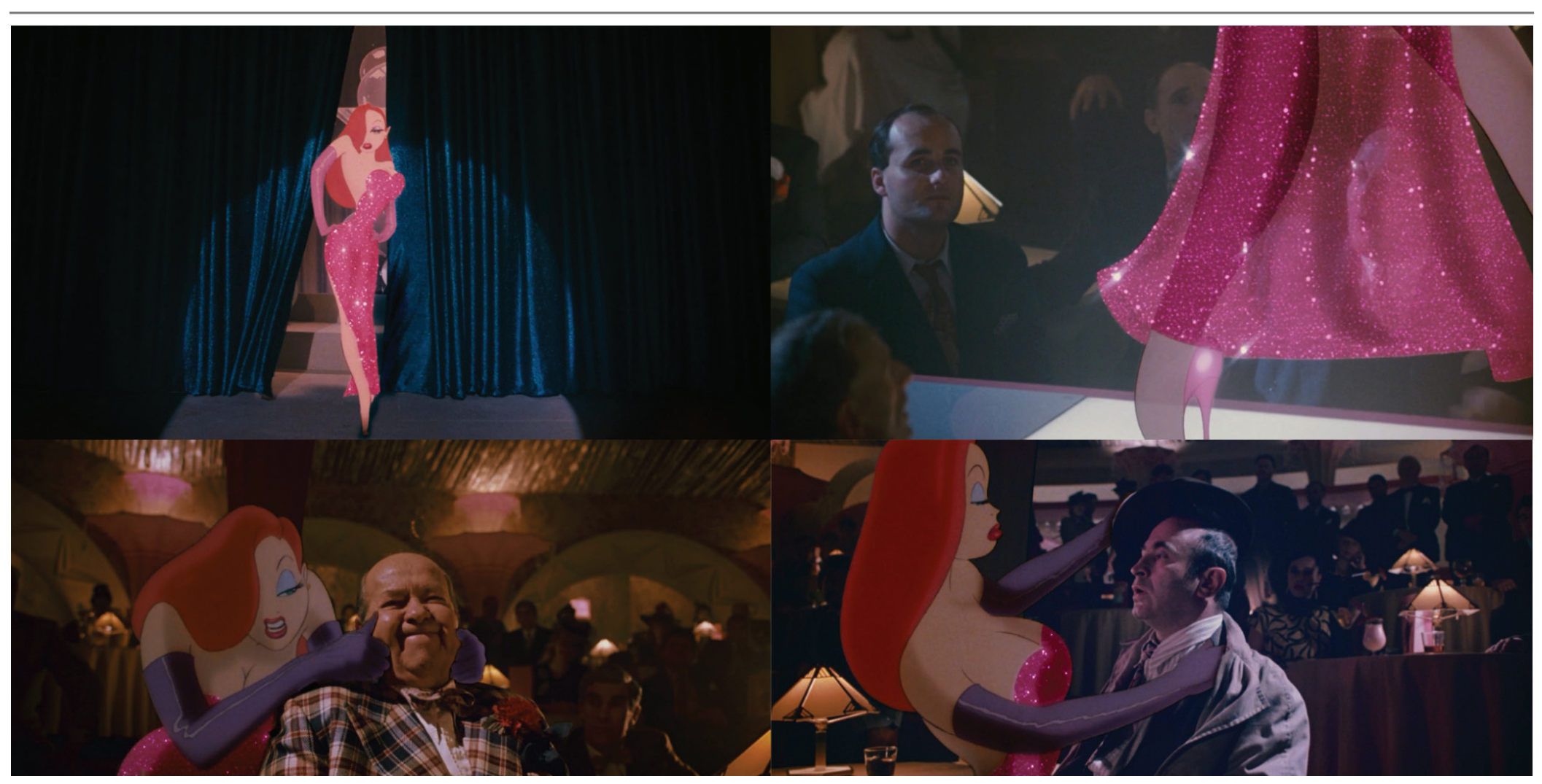

Figura 2: cena de Roger Rabbit

elaborar este pensamento sobre uma animação produzida no ocidente e outra no oriente. Entre os dois desenhos, a inevitável e enriquecedora presença de grandes diferenças conceituais e estéticas, modos de produção e de distribuição. Enquanto Uma Cilada Para Roger Rabbit é um projeto de grandes proporções, envolvendo muita política dentro do sistema de estúdios estadunidense, $O$ Fantasma do Futuro permanece à margem, desenvolvendo-se a partir do estilo único do seu realizador e da sua forma de interpretar tudo que o levou ao filme. Sem esperar que isso possa gerar qualquer distinção ou comparação qualitativa entre os filmes, podemos dizer que um se trata de uma animação comercial e o outro de uma animação de autor. Mesmo sendo uma distinção perigosa, ela apre- senta-nos formas de entender o cinema digital a partir da pré-produção dos filmes. É na gênese destes pensamentos onde residem as decisões que possibilitaram a junção do cartoone do live-action, ou de misturar imagens de CGI em uma animação tradicional - da forma como estas imagens de computador foram usadas.

Para além da produção, os filmes reservam um pensamento profundo a cerca daquilo que elaboram na prática. O pensamento dos corpos e das suas interações torna-se, em ambos os filmes, uma forma de pensar as diversas realidades presentes em cada um. O que acontece, em ambos os filmes, é a junção de duas realidades a princípio distantes, de corpos que pertencem a formas diferentes de realidades, mas que são capazes de interagir com ou-

76 PORTO ALEGRE | v. 19 | n. 32 | 2014 | pp. 70-77 Sessões do Imaginário 
tros corpos de outra realidade. Tal pensamento tornou-se possível apenas pela existência de novos meios técnicos ligados à computação gráfica e aos meios digitais de edição e criação de imagens. Não fosse a existência deste novo meio, enquanto técnica e enquanto uma nova realidade capaz de gerar outros sentidos, até então incapazes de serem explorados de forma tão aproximada, os filmes acabariam tornando-se uma forma de representação falando de outra, e não duas formas de representação em diálogo aberto e contíguo.

\section{Referências}

BIRD, Lawrence. States of emergency: urban space and the robotic body in the metropolis Tale. Mechademia 3, 2008. Disponível em: <http://www.academia.edu/1014330/States_of_Emergency_Urban_Space_and_the_Robotic_Body_in_the_Metropolis_Tales> Acesso em: 08 Jun. 2014.

BORDWELL, David; THOMPSON, Kristin. Film art: an introduction. New York: McGraw-Hill, 7a Ed, 2003.

COHN, Neil; TAYLOR-WEINER, Amaro; GROSSMANG, Suzanne. Framing attention in Japanese and American comics: cross-cultural differences in attentional structure. Frontiers in Psychology, Madford, Setembro de 2012. Disponível em:

<http://journal.frontiersin.org/Journal/10.3389/ fpsyg.2012.00349/full> Acesso em:08 Jun. 2014.

HARTMANN, Nicolai. New ways of ontology: new Introduction by Predrag Cicovacki. Chicago: Transaction Publishers, 2012.

\section{Referências audiovisuais}

HAND, David. Snow White and the seven dwarfs. [Filme-vídeo]. Produção de Walt Disney, direção de David Hand. EUA, 1937. 83 min. color. son.

LISBERGER, Steven. Tron. [Filme-vídeo]. Direção de Steven Lisberger. EUA, 1982. 96 min. color. son.

OSHII, MAMORU. Kôkaku Kidôtai. [Filme-vídeo]. Produção de Bandai Visual Company, Kodansha, Production, direção de Mamoru Oshii. Japão, 1995. 83 min. color. son.

RINTARO. Metoroporisu. [Filme-vídeo]. Direção de Rintaro. Japão, 2001. 108 min. color. son.

ZEMECKIS, ROBERT. Who framed Roger Rabbit. [Filme-vídeo]. Produção de Touchstone Pictures, Amblin Entertainment, Silver Screen Partners III e Walt Disney Feature Animation, direção de Robert Zemeckis. EUA, 1988. 104 min. color. son.

\section{Notas}

1 Mestranda do Programa de Pós-Graduação em Comunicação e Informação da Universidade Federal do Rio Grande do Sul (UFRGS). (PPGCOM/UFRGS - Rua Ramiro Barcelos, 2705, $2^{\circ}$ andar, Santana, CEP: 90.035-007, Porto Alegre/RS, Brasil) E-mail: angela.longo.t@gmail.com.

2 Licenciatura em Artes Visuais pela Universidade Federal do Rio Grande do Sul (UFRGS) e em Estudos Artísticos pela Universidade de Coimbra. (UFRGS Instituto de Artes - R. Senhor dos Passos, 248, Centro, CEP: 90020-180, Porto Alegre/ RS, Brasil). E-mail: planetamalkavo@hotmail.com.
3 Mestranda do curso de Estudos Artísticos da Universidade de Coimbra. Departamento de História, Arqueologia e Artes/Faculdade de Letras, $5^{\circ}$ andar - Largo da Porta Férrea, 3004-530, Coimbra, Portugal. E-mail: deniseliege@gmail.com.

4 Licenciatura em Artes Visuais pela Universidade Federal do Rio Grande do Sul (UFRGS) e em Estudos Artísticos pela Universidade de Coimbra. (UFRGS Instituto de Artes - R. Senhor dos Passos, 248, Centro, CEP: 90020-180, Porto Alegre/ RS, Brasil). E-mail: mayciana@gmail.com.

5 http://youtu.be/egRAxn8DiQc, acedido no dia 08 de Junho de 2014.

6 Usando como exemplo o longa-metragem Princesa Mononoke (Mononoke-Hime, Hayao Miyazaki, 1997), os escritores apresentam o exemplo de um filme de animação que reproduz, em computador, células de animação. Assim sendo, na cena referida na pág. 166 do livro, cinco porções de um plano foram inseridas via computador, tornando a imagem muito mais fluída, e com movimentos mais complexos do que seria possível fazer em células de animação, e ainda assim tornando essa manipulação digital virtualmente irreconhecível, preservando com rigor a estética da animação. 